\title{
Response
}

\section{Early Assessment of the Risk for Gestational Diabetes Mellitus: Can Fasting Parameters of Glucose Metabolism Contribute to Risk Prediction? (Diabetes Metab J 2019;43:785-93)}

\author{
Christian S. Göbl ${ }^{1}$, Andrea Tura ${ }^{2}$ \\ ${ }^{1}$ Division of Obstetrics and Feto-Maternal Medicine, Department of Obstetrics and Gynecology, Medical University of Vienna, Vienna, \\ ${ }^{2}$ Metabolic Unit, CNR Institute of Neuroscience, Padova, Italy
}

We appreciate the interest in our article and would like to thank the editor to give us the opportunity to respond to the thoughtful comments by Drs Yang und Jung.

We agree that fasting (or static) indices of glucose metabolism, which were used in our study, cannot fully reflect the pathophysiology of gestational diabetes mellitus (GDM), although, these indices have some interesting properties [1]. Their major advantage is that they are easy to obtain by a simple blood sample at fasting condition; therefore, they are cheaper and less time consuming as compared to dynamic indices based on frequently sampled intravenous or oral glucose tolerance tests. Especially regarding the estimation of insulin sensitivity, a previous study concluded that static surrogate measures of insulin action appeared to be typically acceptable, and sometimes nearly as good as dynamic indices derived from the oral glucose tolerance test [2]. In line with these findings we observed that a modified quantitative insulin sensitivity check index (QUICKI) showed good properties to identify patients with risk for GDM and especially those with need of glucose lowering medications already at early gestation.

As further pointed out by Drs Young and Jung the predictive power may be increased by using one variable representing both the amount of insulin sensitivity and secretion. This could be achieved by the disposition index (an index of $\beta$-cell secretion that accounts for insulin resistance), which is traditionally calculated as the product of insulin action and insulin secretion [3]. While this is an interesting idea, we have consciously not included a "modified" disposition index in our study due to several concerns as in detail reviewed by [4]. First, a correct calculation of the disposition index ideally would require that insulin sensitivity and secretion are calculated from different tests (i.e., that they are not intrinsically interdependent). This is generally not true if both indices are derived from fasting conditions as it was the case in our study. Second, the disposition index should assume a hyperbolic relationship between insulin action and secretion, which may not exist for indices derived from fasting condition.

Finally, we agree with Drs Young and Jung that the potential clinical benefit of early interventions in women with high risk for GDM needs to be evaluated in prospective studies.

\section{CONFLICTS OF INTEREST}

No potential conflict of interest relevant to this article was reported.
Corresponding author: Christian S. Göbl (iD https://orcid.org/0000-0002-3922-7443

Division of Obstetrics and Feto-Maternal Medicine, Department of Obstetrics and Gynecology, Medical University of Vienna, Waehringer Guertel 18-20, A-1090 Vienna, Austria

E-mail: christian.goebl@meduniwien.ac.at
This is an Open Access article distributed under the terms of the Creative Commons Attribution Non-Commercial License (https://creativecommons.org/licenses/by-nc/4.0/) which permits unrestricted non-commercial use, distribution, and reproduction in any medium, provided the original work is properly cited. 


\section{REFERENCES}

1. Falcone V, Kotzaeridi G, Breil MH, Rosicky I, Stopp T, Yerlikaya-Schatten G, Feichtinger M, Eppel W, Husslein P, Tura A, Gobl CS. Early assessment of the risk for gestational diabetes mellitus: can fasting parameters of glucose metabolism contribute to risk prediction? Diabetes Metab J 2019;43:785-93.

2. Otten J, Ahren B, Olsson T. Surrogate measures of insulin sensitivity vs the hyperinsulinaemic-euglycaemic clamp: a meta- analysis. Diabetologia 2014;57:1781-8.

3. Kahn SE, Prigeon RL, McCulloch DK, Boyko EJ, Bergman RN, Schwartz MW, Neifing JL, Ward WK, Beard JC, Palmer JP. Quantification of the relationship between insulin sensitivity and beta-cell function in human subjects. Evidence for a hyperbolic function. Diabetes 1993;42:1663-72.

4. Mari A, Ahren B, Pacini G. Assessment of insulin secretion in relation to insulin resistance. Curr Opin Clin Nutr Metab Care 2005;8:529-33. 